\title{
Ecological succession and the climax community on a marine subtidal rock wall
}

\author{
Richard R. Vance \\ Department of Biology, University of California, Los Angeles, California 90024, USA
}

\begin{abstract}
Persistence and development of an epibiotic community occupying a temperate, marine, subtidal rock wall was studied for $4.5 \mathrm{yr}$. Composition and abundance of the biota of unmanipulated control quadrats remained remarkably constant. Fleshy red algae fluctuated seasonally, and other taxa fluctuated aperiodically, but abundances of all taxa remained within rather narrow limits. To determine the repeatability of succession, quadrats were cleared of all residents in summer and in winter in each of 2 yr. The encrusting bryozoans and annelids that occur commonly in other areas heavily grazed by sea urchins quickly colonized the cleared quadrats but within 1 to 3 yr gave way to the assemblage that characterizes uncleared areas. With minor variations, all quadrats had nearly converged quantitatively to the control condition by about $3 \mathrm{yr}$ after clearing. A third set of quadrats was caged to exclude all macropredators ( 1 starfish and 3 grazing fishes). Density of the epibiatic mat increased and some changes in the growth forms of some organisms occurred, but no major, lasting changes in abundances were observed over $3 \mathrm{yr}$. These and other observations suggest that the high local taxonomic diversity here must arise mainly not from external disturbances but from interactions between the sessile epibiotic species themselves.
\end{abstract}

\section{INTRODUCTION}

Do natural ecological communities regain their original taxonomic composition following radical alteration by major external disturbances? If so, is there a repeatable successional sequence of species replacements through which each community passes while returning to its original composition? To what extent does a community's natural composition depend on such external disturbances for its perpetuation? These 3 interrelated questions play central roles in contemporary ecology because they relate in some way to the evolution of most organisms' ecological attributes and to the resulting emergent properties of the communities that these species comprise. Accordingly, these questions figure prominently both in ecological theories (May 1974, 1976, Roughgarden 1987) and in our empirically based conception of how natural communities function (Erlich \& Roughgarden 1987, Ricklefs 1988).

Answers to these questions vary greatly from one natural community to another and appear nearly as diverse as the earth's communities themselves. Early ecologists viewed terrestrial plant succession as a highly ordered deterministic process, and their principal research goal was to document both this regularity and the inevitable convergence of successional sequences in all natural environments to some kind of self-perpetuating climax community (Clements 1920). In recent decades, considerable disagreement has arisen as to whether populations exhibit strong internally generated regularity at all (e.g. Andrewartha \& Birch 1954, Strong et al. 1984), and the concept of ecological succession is sometimes viewed as irrelevant to nature even as an idealized description.

Studies of marine epifaunal communities have greatly advanced appreciation of the pivotal roles of biotic and abiotic disturbances in controlling community composition. Paine's $(1966,1976)$ original work in the rocky intertidal zone established that much of the diversity of such communities depends heavily on the activities of predators that interrupt and indeed sometimes reverse the outcome of space competition between sessile species. Many investigations since on intertidal and subtidal predator-prey interactions have corroborated this qualitative idea. Sousa (1979a, b, 1980) showed that physical disturbances caused by storms can also diversify communities and introduce considerable variability into the course and end product of succession. Sutherland $(1974,1975,1978,1981)$ and Sutherland \& Karlson (1977) documented such a high degree of variability in the fouling community of 
Beaufort, North Carolina (USA), that not even a crude approximation of the regularity claimed for succession in terrestrial plants can be discerned. Similar variability has been observed in many other fouling studies (Haderlie 1969, Osman 1977, 1978, Haderlie \& Donat 1978, Goren 1979, Dean \& Hurd 1980, Russ 1980, Kay \& Keough 1981, Mook 1981, Shin 1981, Chalmer 1982, Field 1982, Green \& Schoener 1982).

These observations seem to imply that perhaps marine epifaunal communities are somehow inherently different from terrestrial communities. Sutherland \& Karlson (1977) point out that epifaunal marine animals lack both roots that extensively modify the substratum and a resting stage comparable to the seeds of terrestrial plants that would enable them to withstand unfavorable environmental periods. Without these stabilizing features, perhaps marine epifaunal communities are always unstable and/or so heavily controlled by disturbances that the ideals of succession and community stability simply do not apply. The purpose of this study was to learn by examining one particular natural system whether marine epifaunal communities can ever achieve the kind of regular behavior sometimes claimed for terrestrial systems.

The paper describes long-term observations of the sessile community that occupies a subtidal rock wall in southern California. Permanent quadrats on natural substratum were marked; some were maintained in their natural state, others were cleared of their occupants at various times, and still others were protected from large, mobile predators. Community composition in all quadrats was observed closely for up to $4.5 \mathrm{yr}$ and casually for an additional $4.5 \mathrm{yr}$. From these observations information has been extracted concerning 4 questions: (1) Does the taxonomic composition of this natural community vary through time? (2) Does the community return to its natural taxonomic composition following artificial clearing of the substratum? (3) Does recolonization after artificial clearing follow a repeatable pattern? (4) Does natural disturbance play an important role in maintaining the taxonomic diversity of the community? The first 2 questions concern aspects of community stability, the third involves community succession, and the last explores the connection between succession and community diversity. This report complements shorter-term observations published previously (Vance 1978, 1979, Nelson \& Vance 1979, Vance \& Schmitt (1979) on various species interactions within this community.

\section{METHODS}

Field and laboratory methods. The study area is a vertical rock wall on Bird Rock $\left(33^{\circ} 27^{\prime} \mathrm{N}\right.$ lat., $118^{\circ} 29^{\prime} \mathrm{W}$ long.), a small island located near Santa Catalina Island, about $30 \mathrm{~km}$ south of Los Angeles, California (USA). The wall extends from the surface to about $25 \mathrm{~m}$ depth. The principal study site is a $40 \mathrm{~m}^{2}$ area centered at $15 \mathrm{~m}$ depth. The wall at this site is uniformly vertical. and current and surge subjectively appear relatively constant over the site. The average monthly water temperature ranges from about 14 to $18^{\circ} \mathrm{C}$ through the year. Few holes or crevices inhabitable by the sea urchin Centrostephanus coronatus occur in the immediate vicinity, and the wall supports a dense bed of the sessile clam Chama arcana $(=C$. pellucida in Vance 1978) that provides much of the attachment surface for the epibiotic organisms.

Permanent quadrats were established between 12 and $17 \mathrm{~m}$ depth. No large magnitude systematic differences in taxonomic composition appeared over this depth range at this study site. These quadrats were marked and observed photographically as described earlier (Vance 1979). Briefly, each quadrat was marked by a permanent $25 \times 25 \mathrm{~mm}$ plastic tag. The tag's corners established four $6 \times 9 \mathrm{~cm}$ subquadrats. Four quadrats were established as controls, and the 2 subquadrats of each with the least surface irregularity were selected for long-term monitoring. Uniform surfaces are preferred for photographic monitoring because surface irregularities sometimes complicate identification of resident organisms in photographs. No visually obvious differences developed between photographed and nonphotographed subquadrats. Except for installation and monthly scraping of the quadrat marker to remove attached organisms, these control quadrats were maintained in their natural state. These quadrats were established in November 1974.

Eight quadrats were established as removals. In each of November 1974, June 1975, November 1975, and June 1976, two of these were cleared of all attached. organisms over areas of about $30 \times 30 \mathrm{~cm}$ centered on the marker. The area cleared exceeded the area to be sampled in order to eliminate edge effects. Removal was accomplished by hammer and chisel followed by wire brushing, and the friable nature of the rock made possible essentially complete elimination of surface irregularities of the rock itself, attached valves of Chama arcana, and holes drilled by boring pholad bivalves. The original intent was to monitor all 4 subquadrats of each quadrat, but the time required proved prohibitive. Accordingly, the 2 most uniform subquadrats of each quadrat were selected for long-term monitoring. Again, no visually obvious differences developed between photographed and nonphotographed subquadrats.

Two quadrats were established for predator exclusion. Over these were placed $30 \times 30 \times 8 \mathrm{~cm}$ cages (larger than the area to be sampled to eliminate edge 
effects) made from $3 \mathrm{~mm}$ stainless steel wire woven into a $2.5 \mathrm{~cm}$ mesh. These cages were held in place by a single stainless steel lag bolt at the center. They effectively excluded all but the smallest individuals of the 3 common epibiont-grazing wrasses Pimelometopon pulchrum, Oxyjulis californica, and Halichoeres semicinctus, and the predatory starfish Pisaster giganteus. No other common macropredators occur at this site. No attempt was made to exclude or monitor smaller predators. The cages were replaced each month with cleaned cages to minimize the effects of cage fouling on the enclosed organisms. All 4 subquadrats of each predator exclusion quadrat were monitored. This treatment commenced in March 1975.

Subquadrats were photographed monthly from their initiation until June 1979 except for the predator exclusion treatment which was terminated in March 1978. A Nikonos II camera equipped with a 3:1 extension tube and a photoframe employed 2 strobes mounted on opposite sides of the camera to minimize shadows. Each color slide was projected onto a grid of 50 evenly spaced points at which the identities of the organisms were scored. The monthly sample from the control, predator exclusion, and each of the 4 removal treatments involved 8,8 , and 4 subquadrats, respectively.

I used evenly arranged sample points to expedite the scoring process. Most fouling studies have employed randomly placed points. From a statistical comparison of the 2 methods, Ripley (1981, p. 25) concludes that 'systematic sampling should do well relative to uniform random sampling. Furthermore, we would expect systematic sampling to be best unless [the organisms' distributions have] a strong periodicity with wavelength [equal to] the basic sampling interval.' No such periodicity was observed in this study.

The photographs necessarily recorded only those organisms visible from the surface of the highly 3 dimensional epibiotic mat. Small body size of many of the resident organisms, the presence of attached diatoms, and imperfect focus and lighting frequently prevented identification to species. Accordingly, organisms were routinely classified into several rather inclusive but relatively ecologically homogeneous 'major taxa'. These taxa are listed in Table 1 ; their common species are listed in Table 1 of Vance (1979). The taxa Ascidiacea, Encrusting Bryozoa, Annelida, and Anthozoa are nearly monospecific at this site; at least $95 \%$ of their occurrences are accounted for by Trididemnum opacum, Parasmittina californica, Spirobranchus spinosus, and Corynactis californica, respectively. This classification scheme minimized identification errors and maximized the number of photographs that could be scored in the time available but at the price of rather poor taxonomic resolution in some groups. Resulting data focus attention on abun- dance patterns only of the major taxa as whole groups but, of course, do not reveal individual species' abundance patterns within each major taxon.

By convention, a point was considered occupied by Annelida or Cirripedia only if it fell within about $2 \mathrm{~mm}$ of the opening for the feeding appendages, as the remaining external surface of these organisms itself constitutes potentially inhabitable (and often inhabited) space. Therefore measured abundances of these taxa considerably underestimate the amount of substratum that they covered. Many points were occupied by dead, decayed, and/or heavily fouled organisms. These were identified collectively as 'Debris' and constituted a large fraction of the biota in most samples.

Data analysis. The practical difficulty of field experimentation in the subtidal environment combined with the amount of time required to score the photographs resulted in small sample sizes in all treatments. Statistical analysis and data presentation therefore required the use of several data pooling conventions. These conventions preclude fine partitioning of the variance, and the simple statistical tests that they allow are not very sensitive to small treatment effects. However, these tests are quite sensitive to large magnitude effects associated with many biologically important trends.

In general, between-quadrat variation exceeded within-quadrat variation in all treatments. For the purpose of data presentation, the quadrat is considered as the sampling unit, and the data from all subquadrats of each quadrat were combined. In the figures below, the variation associated with treatment means is expressed as the range in taxon abundances over the separate quadrats within the treatment. For the purpose of statistical analysis, however, the subquadrat is regarded as the sampling unit. Taxon abundances within each subquadrat were averaged over a suitable 6 -mo period (indicated in Table 1 below), and treatments were compared using 2-sample $t$-tests of untransformed data. This time averaging procedure is routinely employed in multiple anova tests using repeated measures (Morrison 1976, p. 156, Dixon 1983, Chap. 15).

Describing the sequence of events during succession and detecting eventual convergence of the community to a steady state constitute 2 separate statistical problems. Assessing the repeatability of successional events requires comparisons between quadrats cleared at different times. Because each removal group in this study contains only 2 quadrats, it is not possible to separate statistically the effect of the time of clearing from the individual quadrat effect. Accordingly, I shall simply describe verbally the major qualitative similarities between quadrats cleared at different times.

These same data, however, allow a more objective statistical assessment of convergence. I have employed 
2 methods. One involves pooling the data from all 4 removal treatments at the end of the observation period into a single removal sample. This combined removal treatment is compared with the control treatment using $t$-tests on taxon abundances within subquadrats. The other method treats each removal period separately and employs 2 summary statistics derived from quadrat data as follows. Let $p_{i k}$ and $q_{i k}$ represent the abundance of taxon $\mathrm{i}$ in removal quadrat $\mathrm{k}$ and control quadrat $\mathrm{k}$, respectively, and let $\overline{\mathrm{q}}_{1}$ represent the average abundance of taxon $i$ in the control quadrats. Define the summary statistics

$$
\begin{aligned}
& \text { DIF }=(1 / 4) \sum_{k=1}^{4}\left\{\sum_{i}\left(q_{i k}-\bar{q}_{1}\right)^{2}\right\}^{1 / 2} \\
& D E V=(1 / 2) \sum_{k=1}^{2}\left\{\sum_{i}\left(p_{i k}-\bar{q}_{i}\right)^{2}\right\}^{1 / 2},
\end{aligned}
$$

which are calculated separately for each date from abundances of living taxa only (i.e. Empty Space and Debris are excluded and taxon abundances are rescaled to sum to 1). DIF measures the degree to which individual control quadrats differ from their mean. It compresses information on all taxa into a single number that resembles a standard deviation. In a similar manner, DEV measures the degree to which individual removal quadrats deviate from the mean of the control quadrats. It is evident from their construction that DEV will approach DIF as the removal quadrats become more similar to the controls.

In general, these ad hoc statistical procedures were chosen because they were easy to apply to the available data. A richer data set would have permitted finer grained statistical examination. Furthermore, alternative statistical procedures with different strengths and sources of error could be employed with the data reported here. I strongly suspect, however, that no reasonable alternative statistical treatment would alter the principal qualititative conclusions reported below.

\section{RESULTS}

\section{Control quadrats}

In comparison with fouling communities (e.g. Sutherland \& Karlson 1977), taxon abundances in control quadrats remained relatively constant over the 4.5 yr of close observation (Fig. 1, Table 1). Not only did mean abundances fail to change dramatically through time, but individual quadrat maxima indicate that no quadrat was ever monopolized by any single taxon. Rather, each quadrat individually supported several coexisting taxa whose abundances did not exhibit violent fluctuations. There occurred only 3 significant changes from the beginning to the end of the observation period, and all were small in magnitude (Table 1). Erect Bryozoa decreased by $5 \%$ cover, Porifera decreased by $10 \%$ cover, and Rhodophyta increased by $9 \%$ cover. The causes of these changes are unknown.

Some of the observed variation in mean taxon abundance was seasonal. Rhodophyta (fleshy red algae) varied in a regularly repeating fashion between about $20 \%$ cover in the summer and $10 \%$ in the winter. This fluctuation probably resulted from the seasonal pattern of light availability. The apparently complementary oscillation in Encrusting Corallinaceae certainly arose as an artifact of photographic sampling. Direct visual inspection of the quadrats revealed that Encrusting Corallinaceae did not decline in summer; rather, the thicker growth of Rhodophyta in that season merely obscured it in photographs.

Some of the variation in taxon abundances followed no obvious pattern. Erect Bryozoa, for example, showed 3 peaks, 2 in summer and 1 in winter. Increased ranges during these periods reveal that these peaks occurred in only some of the quadrats.

Though community composition remained relatively static, there was a continual turnover of some of the resident organisms. Appearance and disappearance of individual organisms or colonies were commonplace in the photographs. Senescent organisms were usually scored as Debris. The fact that Debris always remained abundant suggests that turnover was consistently high.

During the $4.5 \mathrm{yr}$ observation period, there occurred in the control quadrats 10 separate instances of Chama arcana mortality, sometimes involving a single clam. and sometimes a group of adjacent clams. The cause of death was almost certainly predation by Pisaster giganteus. The outer valves were usually missing, and the inner surface of the attached valves provided empty space for colonization by epibionts. Total substrate area exposed by each instance of $C$. arcana mortality, visually estimated from the slides, ranged from 2.5 to $20 \mathrm{~cm}^{2}$, and average renewal rate of empty space by this means was about $3 \% \mathrm{yr}^{-1}$.

Visual observation of sequential monthly photographs revealed that reoccupation of this empty space occurred quickly. Although some colonization must have arisen from newly settled larvae, most reoccupation involved simply lateral expansion of surrounding colonies. The reoccupants were taxonomically diverse but never included the Encrusting Bryozoa and Annelida that colonized the removal quadrats discussed below. The time required for new residents to render the disturbed site visually indistinguishable from the surrounding area averaged 4.3 mo (range: 1 to $12 \mathrm{mo}$ ) and increased with the area of the space originally exposed (Fig. 2). The infrequency of these events, the small surface area involved, and its rapid occupancy mostly by lateral growth of preexisting colonies sug- 
Fig. 1. Mean taxon abundances in control quadrats and in November 1974 removal quadrats. Error bars: range of abundances in individual quadrats. Only taxa whose mean abundance reached $10 \%$ cover on at least 1 sampling date are shown. The control points indicate sampling dates for both treatments; removal points are shifted slightly to the right for clarity
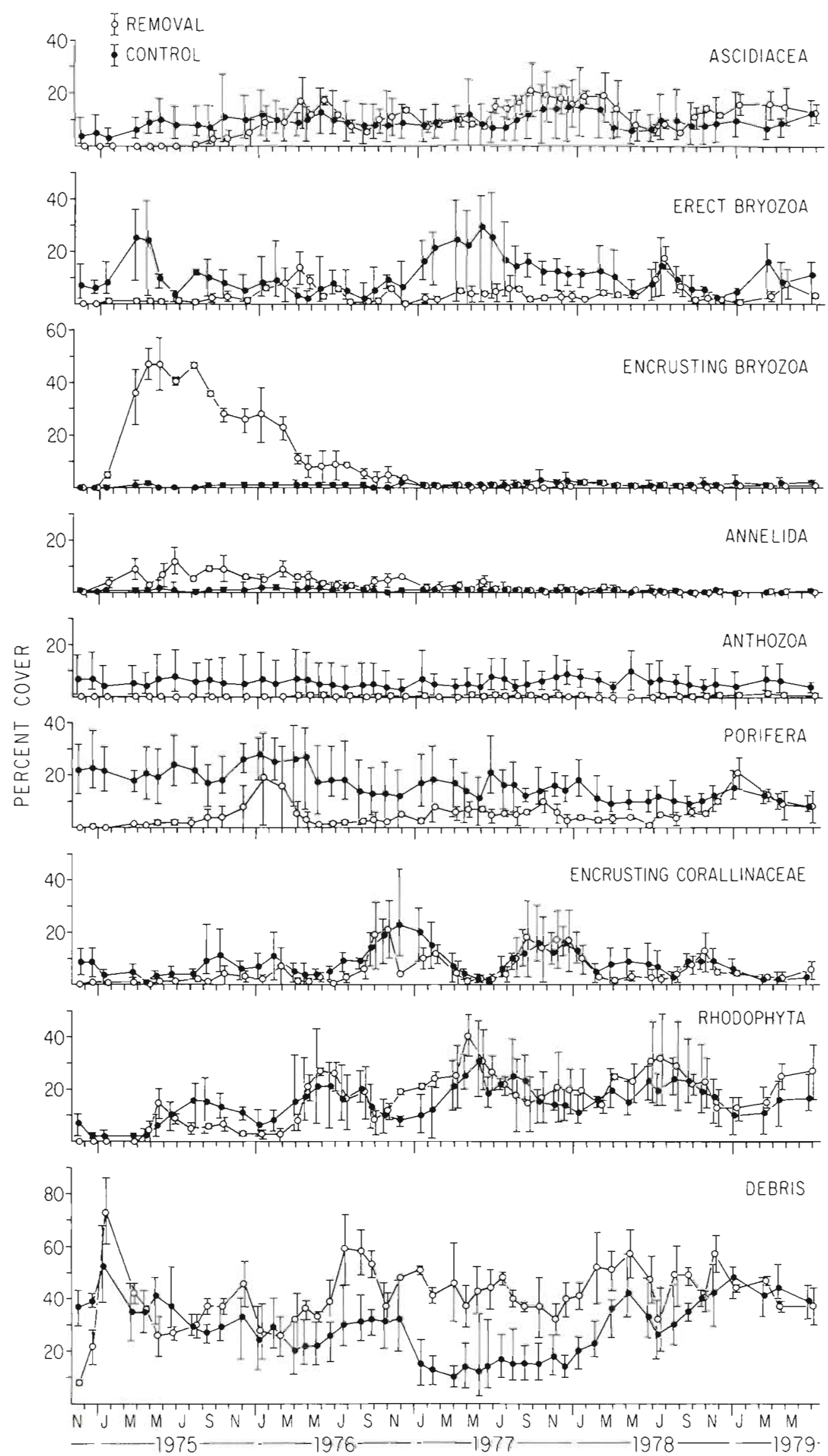
Table 1. Mean taxon abundances (\% cover) over selected 6 mo periods in the various treatments. Student's t-tests were performed on data from individual subquadrats averaged separately over these periods; ${ }^{*}$ and ${ }^{\cdots}$ indicate a difference between the 2 tabulated means in each column with $p<0.05$ and $p<0.01$, respectively

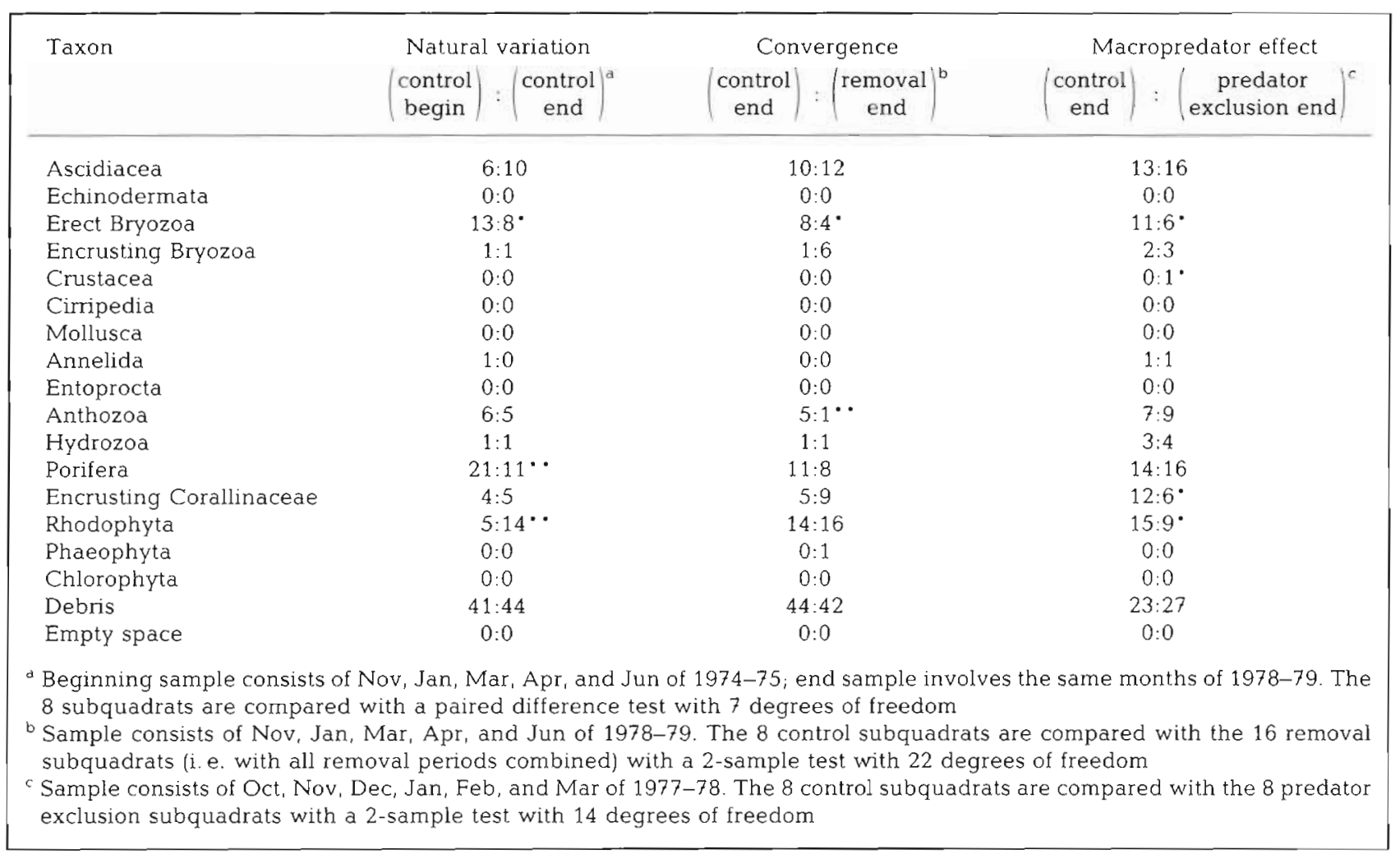

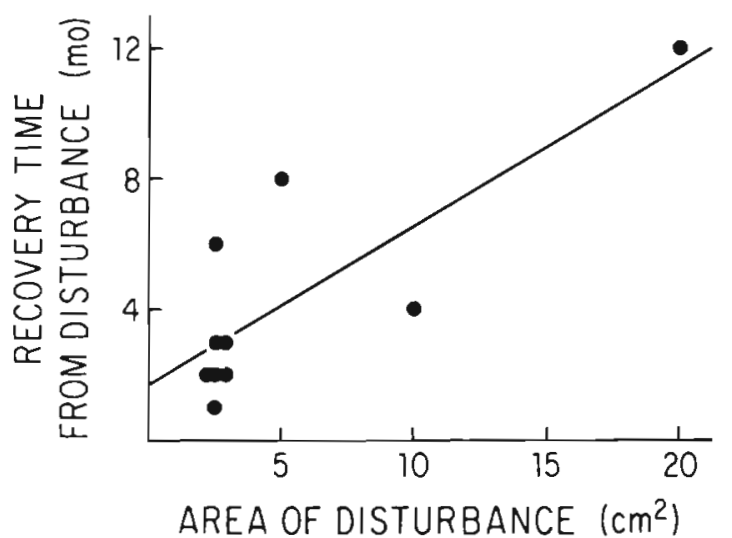

Fig. 2. Time required for small areas of empty space created by Pisaster predation on Chama arcana to become visually indistinguishable from the surrounding undisturbed epibiotic community. Regression equation is $\mathrm{y}=1.76+0.48 \mathrm{x}, \mathrm{R}^{2}=$ 0.65 , and $p<0.01$

gest that this source of disturbance produces no more than a minor effect on community structure.

In summary, these observations portray this natural epibiotic community as a locally diverse assemblage of Rhodophyta, Encrusting Corallinaceae, Porifera, Anthozod, Erect Bryozoa, and Ascidiacea in which taxon abundances remain relatively constant and (on this spatial scale) no taxon consistently or even occasionally monopolizes the substratum.

\section{Removal quadrats}

Taxon abundance data from the November 1974 removal quadrats (Fig. 1) exhibit 2 conspicuous trends. First, the newly cleared quadrats were invaded by 2 taxa which quickly became relatively common and later practically disappeared from the community. Encrusting Bryozoa, mostly the single species Parasmittina californica, began occupying a measurable fraction of the cleared space within 2 mo. By 5 mo, they comprised about $50 \%$ cover, and they remained conspicuous space occupiers for a little over 1 yr after which they declined to the low levels of the control quadrats. Annelids, mostly the single species Spirobranchus spinosus, revealed a similar pattern. They colonized within about 2 mo, remained common for about $2 \mathrm{yr}$, and then declined to control levels. Measured Annelida abundances never reached high levels because only those grid points falling within about $2 \mathrm{~mm}$ of a tube aperture were considered occupied by 
an annelid. These 2 early colonizing species are common residents of perpetually disturbed areas such as the grazing ranges of the sea urchin Centrostephanus coronatus (see Vance 1979).

Second, the various other taxa invaded gradually, in all cases from recruitment by planktonic larvae rather than by lateral expansion of surrounding adult colonies. After about 3 yr their abundances closely approximated the control condition. That is, abundances approached relatively constant levels (compared to fouling communities), repeating seasonal variation appeared in Rhodophyta and Encrusting Corallinaceae, and some unexplained nonseasonal variation occurred in other taxa. By June 1979, the main inhabitants of these quadrats were Rhodophyta, Encrusting Corallinaceae, Porifera, Erect Bryozoa, and Ascidiacea. The main consistent difference from the control quadrats involved Anthozoa which remained practically absent. For unknown reasons, the sea anemone Corynactis californica generally exhibits low recruitment in this area.

The other 3 sets of removal quadrats (Fig. 3) showed these same general trends, though with considerable quantitative variation between treatments. The Encrusting Bryozoan Parasmittina californica was an early invader in every case. Its maximum abundance ranged from 38 to $50 \%$ cover in the separate removals, and its period of high abundance extended from as little as $8 \mathrm{mo}$ to as long as $3 \mathrm{yr}$. In all but the most recent clearing, it had nearly disappeared from the community by June 1979. The annelid Spirobranchus spinosus invaded in both the June 1975 and November 1975 clearings and remained present for $2 \mathrm{yr}$ and $1 \mathrm{yr}$, respectively, and then disappeared. It failed to recruit in the June 1976 clearings. Colonization by the other taxa typically followed these early invaders though with considerable variation in timing. Rhodophyta exhibited seasonal maxima in summer and minima in winter in nearly all cases. Anthozoa never exceeded trace abundances in any removal quadrat.

The removal quadrats nearly converged to the control condition during these experiments (Fig. 4, Table 1). As shown in Fig. 4, DIF remained relatively constant throughout the $4.5 \mathrm{yr}$. Thus, samples of the natural community differed by a fixed amount, on the average, from a (seasonally time-varying) mean state. In all removal treatments, DEV started out at a high level and gradually approached DIF, nearly, but not quite, reaching it after about 3 yr. By the end of the close observation period, the only significant differences between the combined removal subquadrats and the control treatment (Table 1) involved erect Bryozoa and Anthozoa, both of which were less abundant in the removal treatment by $4 \%$ cover.

In June 1979 the removal quadrats could still be visually distinguished (with some difficulty) from their surroundings. Incomplete convergence probably arose in part from the greater topographic uniformity of the removal quadrats than of the controls. The buildup of beds of Chama arcana and the creation of topographic variability in the rock surface itself by burrowing pholad bivalves both require several years. These processes had not returned the substratum to its natural state by the end of the close observation period. Casual visual inspection in November 1983, 9 yr after the earliest clearings, revealed that substratum surface irregularity had by then approached the natural state somewhat more closely. The attached biota so closely resembled the surrounding areas that without their marks most of the removal quadrats were hard or impossible to find.

In summary, these observations reveal that newly cleared space is quickly invaded by taxa characteristic of disturbed sites, that these taxa are gradually replaced by the more diverse suite of more slowly invading organisms that characterize the natural community, and that community composition as a whole approaches the natural state closely within 3 yr and completely within $9 \mathrm{yr}$. This qualitative pattern appears repeatable from year to year and season to season though with some quantitative variation.

\section{Predator exclusion quadrats}

The presence of the cages failed to exert a strong effect on measured taxon abundances (Fig. 5, Table 1). Four significant differences appeared at the end of the experiment (Table 1), but none was large in magnitude. Erect Bryozoa, Encrusting Corallinaceae, and Rhodophyta decreased by $5 \%, 6 \%$, and $6 \%$ cover, respectively, under the cages compared to the control quadrats, while Crustacea increased to $1 \%$ cover. This last change is the tail end of a single large peak in Crustacea under the cages caused by the sudden appearance of numerous unidentified tubiculous amphipods (Fig. 5). These colonized in the fall of 1975 , reached a peak mean abundance of $27 \%$ cover in March 1976, and nearly vanished (probably after one generation) in the fall of 1976, never to reappear in large numbers. Whether these changes were caused by the absence of macropredators or by altered physical conditions within the cages (reduced light levels and flow rates) is not clear, since no attempt was made to control for possible physical cage effects. I strongly suspect that the abundance of amphipods resulted from predator absence because these amphipods are readily eaten by the fish excluded from these quadrats, they naturally occur rather rarely in this environment, and their natural occurrence seems largely restricted to crevices and similar protected places. 


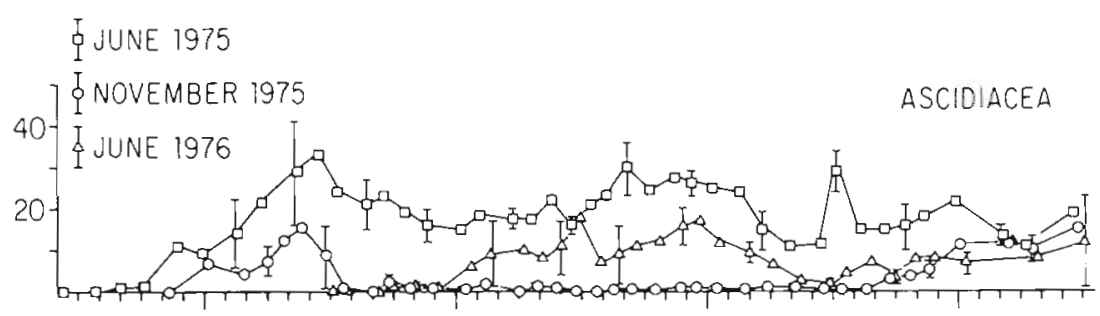

40
20
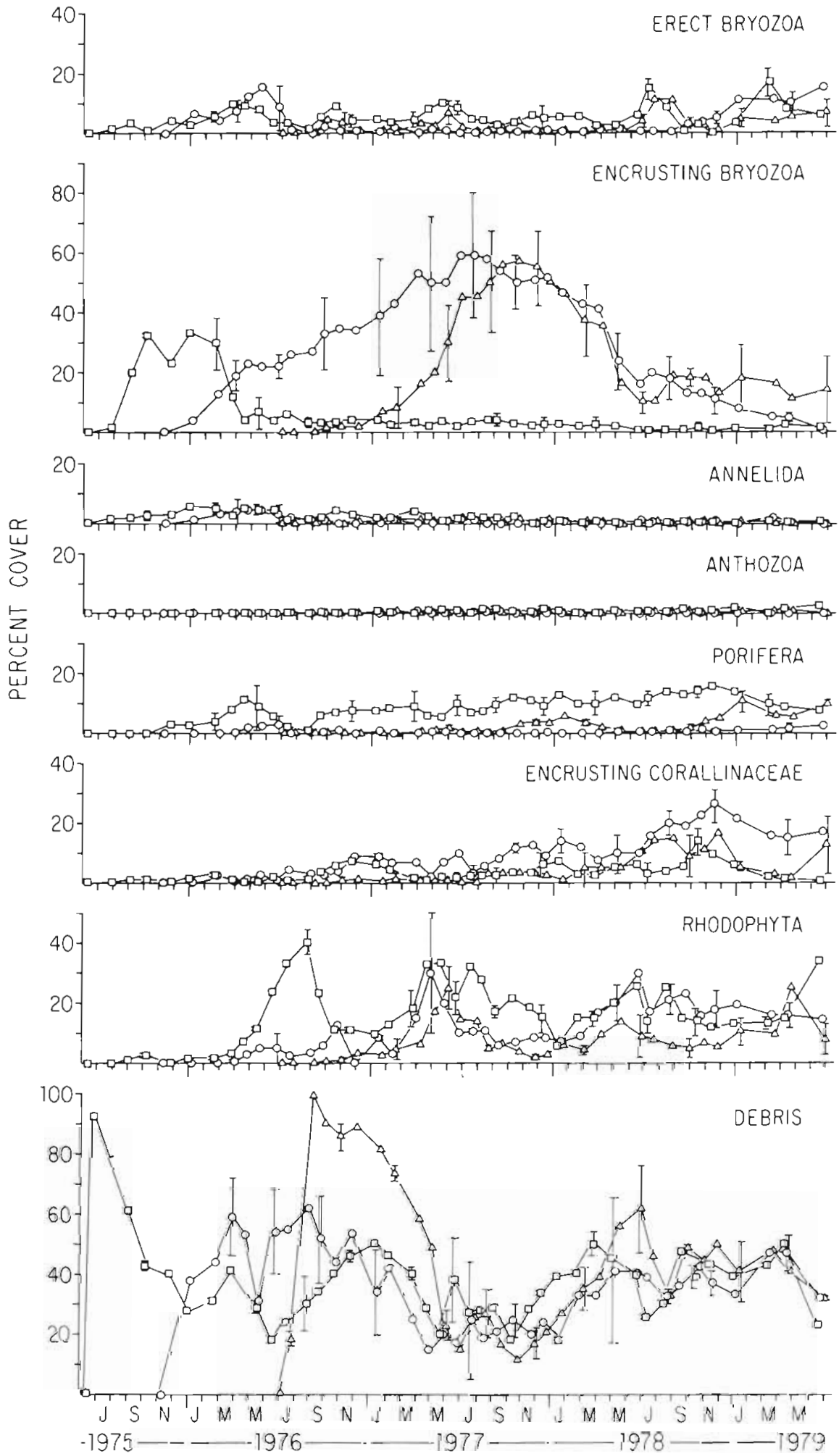

Fig. 3. Mean taxon abundances in June 1975, November 1975, and June 1976 removal quadrats. Ranges are plotted only for every third month to reduce clutter 
Fig. 4. DIF for control quadrats and DEV for removal quadrats plotted against time. The approach of DEV to DIF indicates near convergence of the removal quadrats to the natural state by the end of the close observation period

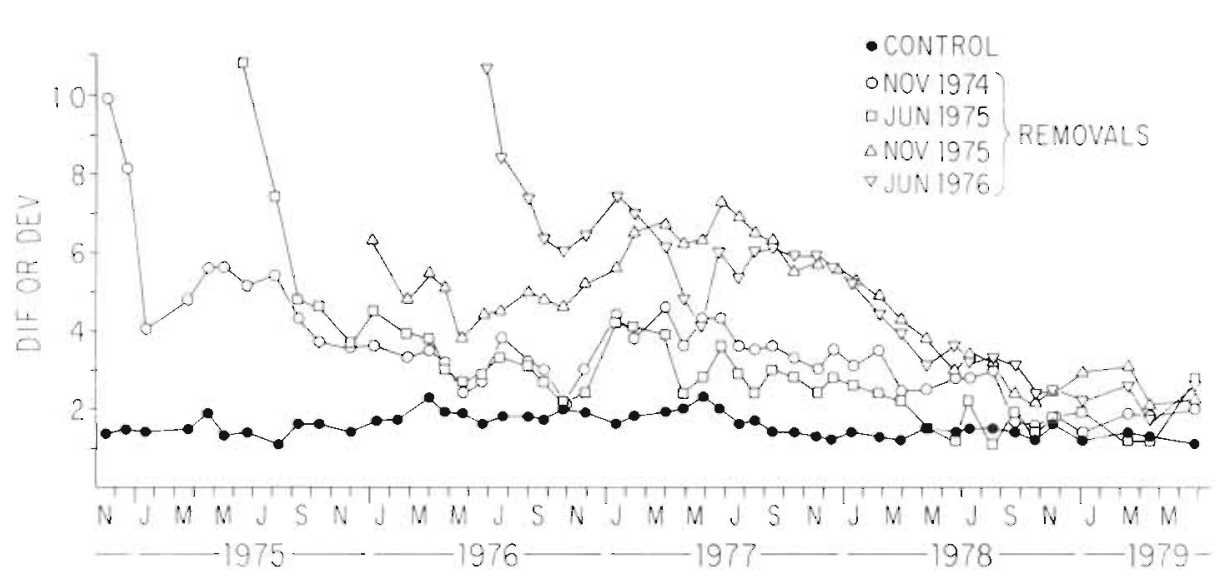

Several additional changes in the caged quadrats were observed during monthly visits to the site, though these are not reflected in taxon abundance data. The epibiotic mat as a whole appeared more lush, probably involved more layers of living organisms, and extended farther from the substratum than in control quadrats. Both sponges and tunicates (especially the colonial species Trididemnum opacum) exhibited an inflated, convex growth form, and sponge tissue seemed somewhat less densely organized than under natural conditions. Associated with this lush epibiotic mat was a discernible buildup of the underlying Chama arcana bed. Cage removal at the end of the experiment caused rapid discovery and consumption of excess $C$. arcana by Pisaster giganteus, and within a few months these quadrats were no longer visually distinguishable from the surrounding area. Again, whether these changes resulted from predator absence or physical cage effects is not clear.

These observations suggest that while macropredators may affect the sizes of some epibiotic populations and the growth forms of some organisms, they exert at most a small effect on relative abundances of the taxa. Macropredators therefore play no more than a minor role in maintaining taxonomic diversity in this attached community.

\section{DISCUSSION}

The natural community of sessile organisms that occupies the Bird Rock wall at $15 \mathrm{~m}$ depth exhibits little fluctuation between seasons or between years either in taxonomic composition or in abundances of the constituent taxa. This relative constancy evidently results from stabilizing factors within the community, because following its complete removal the natural community becomes nearly fully reassembled in the span of about 3 yr and completely recovered within 9 yr. The same qualitative pattern of recolonization occurred in each of
2 seasons in 2 successive years: early invasion of species typical of disturbed sites was followed by gradual reappearance of the diverse suite of more slowly colonizing taxa that characterize the natural community.

My conventions of lumping species into rather broad taxonomic categories and presenting taxon abundances as treatment means undoubtedly exaggerate the regularity of these trends. Even taking this exaggeration into account, however, this regularity contrasts sharply with the erratic species replacements that often characterize fouling communities. Most fouling studies employ settling plates suspended into shallow water from piers or floating docks. The water surrounding these structures is usually characterized by temporally changing spatial gradients in important physical variables like depth, current speed, temperature, and salinity. The sporadic larval recruitment patterns expected in such variable environments (Keough 1983) can produce domination of newly exposed settlement surfaces by a few species. Senescence of early residents eventually releases empty space, but variable recruitment can again lead to a high degree of dominance. The identities of the second wave of colonists may differ from the first, and individual settling plate biotas may never converge to any persistent state.

The high variability that often characterizes fouling community composition probably ultimately depends on environmental variation, because the same general kinds of organisms converge to a nearly equilibrium state in the much less fluctuating physical environment of the $15 \mathrm{~m}$ Bird Rock site. This interpretation is reinforced by observations in shallower areas on the Bird Rock wall exposed to the more changing surface environment. Cleared quadrats at $3 \mathrm{~m}$ depth exhibit greater variability in colonization events, greater differences between quadrats cleared at the same time, and slower convergence (Vance pers. obs.). This kind of community inconstancy has also been observed in deeper water by Peckol \& Searles (1983) in the strongly 
134

Mar. Ecol. Prog. Ser 48: 125-136, 1988
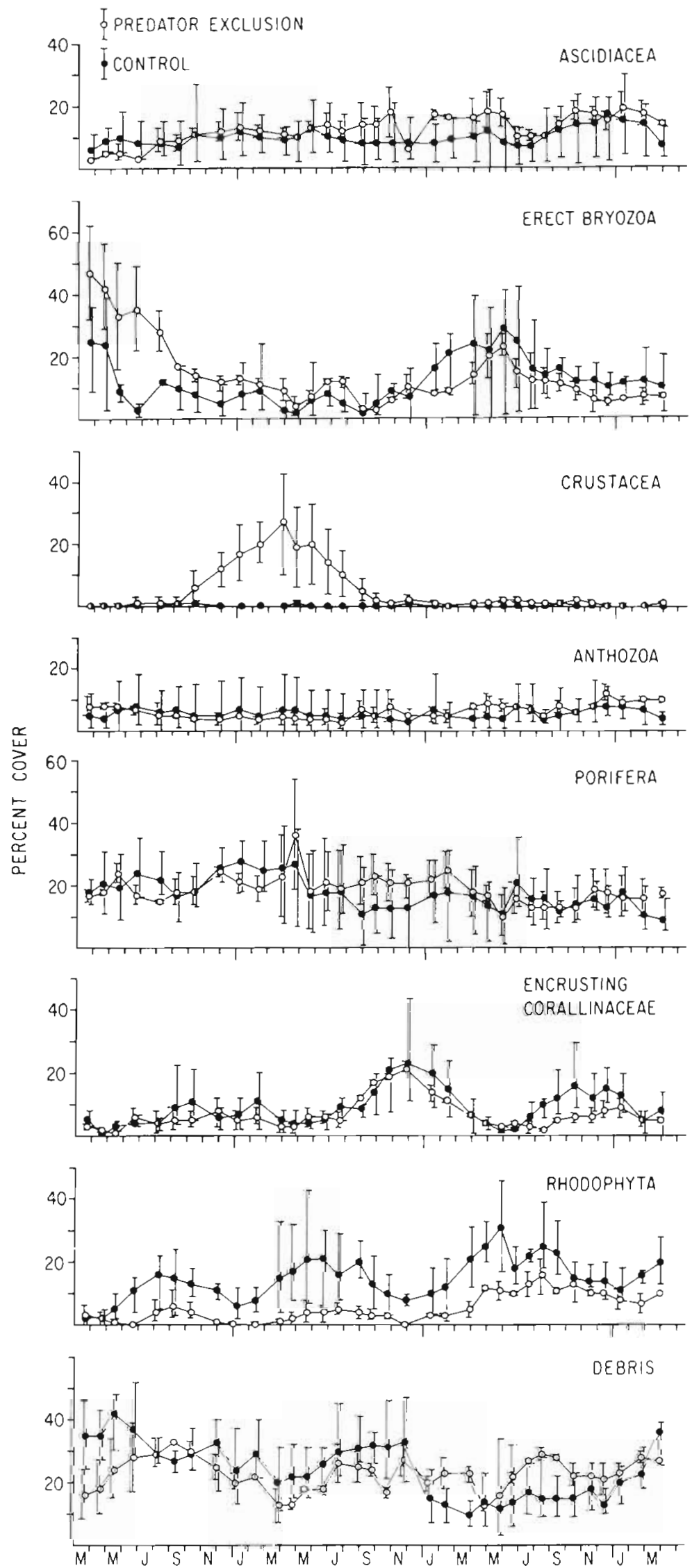

Fig. 5. Mean taxon abundances and ranges in control and predator exclusion quadrat

$1977--1978$ - 
fluctuating subtidal environment of the North Carolina continental shelf.

Factors that cause the high taxonomic diversity at the $15 \mathrm{~m}$ Bird Rock site remain pooly understood. Disturbance at both spatial scales observed in this study appears not to play a major role. Large $\left(1000 \mathrm{~cm}^{2}\right)$ disturbances do not normally occur within Chama arcana beds at this site, and the early colonists following artificial disturbances of this size are not common residents of natural $C$. arcana beds. Such disturbances do occur routinely from grazing by the sea urchin Centrostephanus coronatus near crevices that house them (Vance 1979), and there these colonizing species abound. Therefore, naturally occurring large-scale disturbances do diversify the attached biota of the Bird Rock wall as a whole, but this effect arises as a between-habitat phenomenon. In this respect, the Bird Rock community resembles the pier piling community studied by Sutherland (1978) in North Carolina: the roles of the encrusting bryozoan Parasmittina californica, the annelid Spirobranchus spinosus, and the sea urchin Centrostephanus coronatus at Bird Rock closely parallel those of the encrusting bryozoan Schizoporella unicornis, the annelid Hydroides dianthus, and the sea urchin Arbacia punctulata in North Carolina.

Smaller $\left(10 \mathrm{~cm}^{2}\right)$ disturbances occur occasionally within Chama arcana beds when Pisaster giganteus predation removes the fouled outer shells of the clams and exposes inner shell surface. However, this mechanism renews only about $3 \%$ of the surface area of the $C$. arcana bed per year, and recolonization involves mostly lateral expansion of surrounding colonies, as Kay \& Keough (1981) observed in Australia. Most residents can acquire space in this way, but no taxon seems to depend upon this ability. This impression corroborates the same finding by Mook (1981) in Florida and coincides with Keough \& Butler's (1979) observation that starfish exert little effect on pier piling epifauna in Australia.

The apparent unimportance of disturbance and of predation by large animals suggests that the high taxonomic diversity of this community probably results less from external factors than from interactions between the epibiotic species themselves. Stable coexistence may depend upon several qualitatively different processes all going on at once (Jackson \& Winston 1982) possibly including the effects of micrograzers. Sorting these out will require careful observations on a fine spatial scale along the lines of Buss (1979, 1980, 1981), Jackson (1979), Buss \& Jackson (1981), Jackson \& Winston (1981), Keough \& Downes (1982), Palumbi \& Jackson (1982), and Sebens (1986). In any case, the various patterns observed here show that at least this one marine epifaunal community conforms about as closely to the ideal of succession through regular species replacements as do the terrestrial plant communities that originally inspired creation of the paradigm of ecological succession.

Acknowledgements. A long-term subtidal field investigation of this kind is not possible without the coordinated efforts of a team of dedicated participants. The field work required hundreds of dives and could not have been completed without the substantial enthusiastic assistance of Richard Ambrose, John Benson, Bobette Nelson, and Russel Schmitt, and occasional help from other UCLA and USC graduate students. David Butsumyo scored the majority of the slides, and Craig Pease, with the able assistance of June Baumer, performed the data reduction on the computer Anne Harrington, Sally Holbrook, Bruce Menge, Myra Shulman, John Sutherland, Theresa Tumer, and 5 anonymous referees made helpful comments on an earlier draft of this article. I sincerely thank all of these individuals. The facilities of the University of Southern California Catalina Marine Science Center were kindly made available by the directors, Russell Zimmer and Robert Given. Support was provided by National Science Foundation grant no. DES 75-10017 and the University of California. This paper constitutes contribution no. 90 from the Catalina Marine Science Center

\section{LITERATURE CITED}

Andrewartha, H. G., Birch, L. C. (1954). The distribution and abundance of animals. University of Chicago Press, Chicago, Illinois

Buss, L. W. (1979). Bryozoan overgrowth interactions - the interdependence of competition for space and food. Nature, Lond. 281. 475-477

Buss, L. W. (1980). Competitive intransitivity and size frequency distributions of interacting populations. Proc. natn. Acad. Sci. U.S.A. 77 : 5355-5359

Buss, L. W. (1981). Group living, competition, and the evolution of cooperation in a sessile invertebrate. Science 213 1012-1014

Buss, L. W., Jackson, J. B. C. (1981). Planktonic food availability and suspension-feeder abundance: evidence of in situ depletion. J. exp. mar. Biol. Ecol, 49: 151-161

Chalmer, P. N. (1982). Settlement patterns of species in a marine fouling community and some mechanisms of succession. J. exp. mar. Biol. Ecol. 58: 73-85

Clements, F. E. (1920). Plant succession. an analysis of the development of vegetation. Publication No. 290. Carnegie Institute, Washington, D. C.

Dean, T. A., Hurd, L. E. (1980). Development in an estuarine fouling community: the influence of early colonists on later arrivals. Oecologia (Berl.) 46: 295-301

Dixon, W. J. (1983). BMDP Statistical Software. University of California Press, Berkeley, California

Erlich, P. R., Roughgarden, J. (1987). The science of ecology Macmillan Publishing Co., New York

Field, B. (1982). Structural analysis of fouling community development in the Damariscotta River estuary, Maine. J. exp. mar. Biol. Ecol. 57: 25-33

Goren, M. (1979). Succession of benthic community on artificial substratum at Elat (Red Sea). J exp. mar. Biol. Ecol. 38: $19-40$

Green, C. H., Schoener, A. (1982). Succession on marine hard substrata: a fixed lottery. Oecologia (Berl.) 55: 289-297

Haderlie, E. C. (1969). Marine fouling and boring organisms in Monterey Harbor II. Second year of investigation. Veliger 12: $182-192$ 
Haderlie, E. C., Donat III, W (1978). Wharf piling fauna and flora in Monterey Harbor, California. Veliger 21. 45-69

Jackson, J. B. C. (1979). Overgrowth competition between encrusting cheilostome ectoprocts in a Jamaican cryptic reef environment. J. Anim. Ecol. 48: 805-823

Jackson, J. B. C., Winston, J. E. (1981). Modular growth and longevity in bryozoans. In: Larwood, G. P., Nielsen, C. (eds.) Recent and fossil bryozoa. Olsen and Olsen, Fredensborg, Denmark

Jackson, J. B. C. (1982). Ecology of cryptic coral reef communities. I. Distribution and abundance of major groups of encrusting organisms. J. exp. mar. Biol. Ecol. 57: 135-147

Kay, A. M., Keough, M. J. (1981). Occupation of patches in the epifaunal communities on pier pilings and the bivalve Pinna bicolor at Edithburgh, South Australia. Oecologia (Berl.) 48: 123-130

Keough, M. J. (1983). Patterns of recruitment of sessile invertebrates in two subtidal habitats. J. exp. mar. Biol. Ecol. 66: $213-245$

Keough, M. J., Butler, A. J. (1979). The role of asteroid predators in the organization of a sessile community on pier pilings. Mar. Biol. 51: 167-177

Keough, M. J., Downes, B. J. (1982). Recruitment of marine invertebrates: the role of active larval choices and early mortality. Oecologia (Berl.) 54: 348-352

May, R. M. (1974). Stability and complexity in model ecosystems, 2nd edn. Princeton University Press, Princeton, New Jersey

May, R. M. (1976). Theoretical ecology: principles and applications. Blackwell Scientific Publications, Oxford, England

Mook, D. H. (1981). Effects of disturbance and initial settlement on fouling community structure. Ecology 62: 522-526

Morrison, D. F. (1976). Multivariate statistical methods, 2nd edn. McGraw-Hill, New York

Nelson, B. V., Vance, R. R. (1979). Diel foraging patterns of the sea urchin Centrostephanus coronatus as a predator avoidance strategy. Mar. Biol. 51: 251-258

Osman, R. W. (1977). The establishment and development of a marine epifaunal community. Ecol. Monogr. 47 37-63

Osman, R. W. (1978). The influence of seasonality and stability on the species equilibrium. Ecology 59: 383-399

Paine, R. T (1966). Food web complexity and species diversity. Am. Nat. 100: 65-75

Paine, R. T (1976). Size-limited predation. an observational and experimental approach with the Mytilus-Pisaster interaction. Ecology 57.858-873

Palumbi, S. R., Jackson, J. B. C. (1982). Ecology of cryptic coral reef communities. II Recovery from small disturbance events by encrusting bryozoa: the influence of 'host species and lesion size. J. exp. mar. Biol. Ecol. 64: 103-115

Peckol, P., Searles, R. B. (1983). Effects of seasonality and disturbance on population development in a Carolina continental shelf community. Bull. mar. Sci. 33: 67-86
Ricklefs, R. E. (1988). Ecology, 3rd edn. Chiron Press, New York

Ripley, B. D. (1981). Spatial statistics. John Wiley and Sons New York

Roughgarden, J. (1987). Theory of population genetics and evolutionary ecology: an introduction, revised edn. Macmillan Publishing Co., New York

Russ, G. R. (1980). Effects of predation by fishes, competition, and structural complexity of the substratum on the establishment of a marine epifaunal community. J. exp. mar Biol. Ecol. 42: 55-69

Sebens, K. P. (1986). Spatial relationships among encrusting marine organisms in the New England subtidal zone. Ecol. Monogr. 56: 73-96

Shin, P. K. S. (1981). The development of sessile epifaunal communities in Kylesalia, Kilkieran Bay (West Coast of Ireland). J. exp. mar. Biol. Ecol. 54: 97-111

Sousa, W. P. (1979a). Disturbance in marine intertidal boulder fields: the nonequilibrium maintenance of species diversity. Ecology 60: 1225-1239

Sousa, W. P. (1979b). Experimental investigations of disturbance and ecological succession in a rocky intertidal algal community. Ecol. Monogr. 49: 227-254

Sousa, W. P. (1980). The responses of a community to disturbance: the importance of successional age and species' life histories. Oecologia (Berl.) 45: 72-81

Strong, D. R. Jr, Simberloff, D., Abele, L. G., Thistle, A. B (1984). Ecological communities: conceptual issues and the evidence. Princeton University Press, Princeton, New Jersey

Sutherland, J. P. (1974). Multiple stable points in natura. communities. Am. Nat. 108: 859-873

Sutherland, J. P. (1975). Life histories and the dynamics of fouling communities. In: Costlow, J. D. (ed.) The ecology of fouling communities. U. S. Naval Institute Press, Anapolis

Sutherland, J. P. (1978). Functional roles of Schizoporella and Styela in the fouling community at Beaufort, North Carolina. Ecology 59: 257-264

Sutherland, J. P. (1981). The fouling community at Beaufort North Carolina: a study in stability. Am. Nat. 118: 499-519

Sutherland, J. P., Karlson, R. H. (1977). Development and stability of the fouling community at Beaufort. North Carolina. Ecol. Monogr. 47: 425-446

Vance, R. R. (1978). A mutualistic interaction between a sessile marine clam and its epibionts. Ecology 59: 679-685

Vance, R. R. (1979). Effects of grazing by the sea urchin, Centrostephanus coronatus, on prey community composition. Ecology 60: 537-546

Vance, R. R., Schmitt, R. J. (1979). The effect of the predatoravoidance behavior of the sea urchin, Centrostephanus coronatus, on the breadth of its diet. Oecologia (Berl) 44 $21-25$ 